\title{
Impact of the Climate Matters Program on Public Understanding of Climate Change $\mathscr{}$
}

\author{
Teresa A. Myers AND EdWARd W. MAIBACH \\ George Mason University, Fairfax, Virginia \\ BERNADETTE WoOdS PLACKY \\ Climate Central, Princeton, New Jersey
}

KIMBERLY L. HENRY

Colorado State University, Fort Collins, Colorado

MichaEL D. SLATER

The Ohio State University, Columbus, Ohio

KEITH L. SEITTER

American Meteorological Society, Boston, Massachusetts

(Manuscript received 11 March 2020, in final form 5 July 2020)

\begin{abstract}
Climate Matters is a localized climate change reporting resources program developed to support television (TV) weathercasters across the United States. Developed as a pilot test in one media market in 2010, it launched nationwide in 2013; in the autumn of 2019 more than 797 weathercasters were participating in the program. In this paper we present evidence of the impact of the Climate Matters program on Americans' science-based understanding of climate change. We analyzed three sets of data in a multilevel model: 20 nationally representative surveys of American adults conducted biannually since $2010(n=23635)$, data on when and how frequently Climate Matters stories were aired in each U.S. media market, and data describing the demographic, economic, and climatic conditions in each media market. We hypothesized that 1) reporting about climate change by TV weathercasters will increase science-based public understanding of climate change and 2) this effect will be stronger for people who pay more attention to local weather forecasts. Our results partially support the first hypothesis: controlling for market-level factors (population size, temperature, political ideology, and economic prosperity) and individual-level factors (age, education, income, gender, and political ideology), there is a significant positive association between the amount of Climate Matters reporting and some key indicators of science-based understanding (including that climate change is occurring, is primarily human caused, and causes harm). However, there was no evidence for the second hypothesis. These findings suggest that climate reporting by TV weathercasters, as enabled by the Climate Matters program, may be increasing the climate literacy of the American people.
\end{abstract}

Denotes content that is immediately available upon publication as open access.

Supplemental information related to this paper is available at the Journals Online website: https://doi.org/10.1175/WCAS-D-200026.s1.

Corresponding author: Edward W. Maibach, emaibach@gmu.edu

\section{Overview and purpose of the Climate Matters program}

The most recent U.S. National Climate Assessment (Jay et al. 2018) opens by stating:

Earth's climate is now changing faster than at any point in the history of modern civilization, primarily as a result of human activities. The impacts of global climate change are already being felt in the United States and are projected to intensify in the future-but the severity of future impacts 
will depend largely on actions taken to reduce greenhouse gas emissions and to adapt to the changes that will occur.

Given this reality of human-caused climate change, it is imperative that Americans and people worldwide understand these impacts and risks-especially those happening in their community-so that they can make informed decisions about how to manage the risks, individually and collectively (Lorenzoni et al. 2005; Pidgeon 2012; Maibach 2019).

While a solid majority of Americans understand that climate change is occurring (69\%), many fewer think that they $(44 \%)$, their family $(48 \%)$, people in their community $(48 \%)$, and people in the United States $(59 \%)$ will be harmed by global warming (Leiserowitz et al. 2019). Moreover, most Americans see climate change as a distant threat-in space (somewhere else, not here), time (at some point in the future, but not yet), and species (polar bears, but not people) —and they fail to recognize that it is already causing harm (Ballew et al. 2019).

Television (TV) weathercasters are uniquely well situated to help the American people become more climate literate (Maibach et al. 2016). They are among Americans' most trusted sources of information about climate change (Leiserowitz et al. 2015). They have considerable reach and timely access to the public (Pew Research Center 2013), and their audiences are large and diverse - in income, education, and race/ethnicity (DeMuth et al. 2011). Most are trained in meteorology or other relevant sciences, giving them a strong educational background to understand the causes and consequences of climate change, and nearly all are highly skilled science communicators (Henson 2010). Perhaps most importantly, many express an interest in informing their viewers about the local impacts of climate change (Maibach et al. 2015).

The Climate Matters (CM) program was created to engage and support members of the broadcast meteorology community in climate change reporting. Operated as a partnership between a university (George Mason University), a nonprofit organization (Climate Central), two government agencies (NASA and NOAA), and the American Meteorological Society (AMS), Climate Matters is funded by the National Science Foundation and several philanthropic foundations. The program was designed in response to extensive formative research with TV weathercasters, including in-depth interviews (Rowan et al. 2018) and a survey of all broadcast members of the AMS and the National Weather Association (NWA; Maibach et al. 2010). This formative research revealed that many weathercasters were interested in reporting on climate change, although few actually did. The obstacles that impeded climate reporting included a lack of time for field reporting, perceived scientific uncertainty about climate change, lack of access to trusted scientific information, and lack of access to appropriate visuals/graphics to use in reporting (Maibach et al. 2010).

The Climate Matters program aims to reduce the obstacles to climate reporting and enable local climate reporting by developing and offering a range of educational and localized climate reporting resources. These resources include half- and full-day workshops and oneor two-hour conference sessions (conducted annually at AMS and NWA annual meetings and on a one-off basis at various other venues including NASA and the National Center for Atmospheric Research), webinars, and weekly story packages that include broadcast quality graphics of data that are produced in English and Spanish (Placky et al. 2015). The story packages include a narrative description of the content displayed (including the methodology by which the graphics were produced) and often feature localized information, because local news focuses primarily on locally relevant events. The story packages also aim to be relevant to current weather and seasonal climatic conditions, or to other events in the news cycle (e.g., Halloween, Superbowl Sunday), so as to include a news hook whenever possible (see Figs. 1-4 for examples of Climate Matters graphics, and visit https:// medialibrary.climatecentral.org/ for an archive of past Climate Matters package releases). Broadcast meteorologists utilize these materials in a number of ways, including using them in their on-air weather segments (the most typical use), reporting longer-format on-air news stories outside of the weather segment, posting them to social media with comments, using them in print reporting on their station or personal blog, and in their in person public presentations (at schools and community events).

\section{Growth in weathercaster reporting about climate change}

Most Americans want to hear from weathercasters about climate change (Perkins et al. 2017). Many weathercasters have responded to this opportunity by becoming active in climate reporting and education (Timm et al. 2020), although some weathercasts continue to experience barriers to reporting about climate change (Meldrum et al. 2017).

All of the evidence collected to date suggests that the Climate Matters program has played an important role in helping mainstream the practice of climate reporting by TV weathercasters. Started as a 1-yr pilot test at one TV station (WLTX in Columbia, South Carolina) in 2010, evidence began to emerge almost immediately 


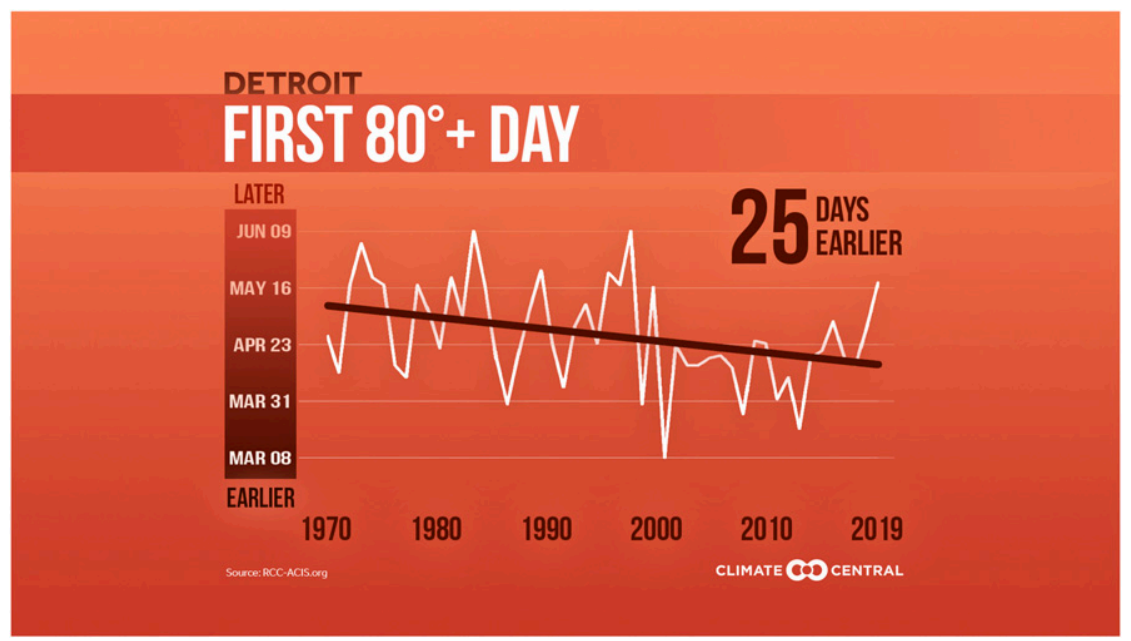

FIG. 1. Example of a warm-weather Climate Matters graphic.

about the value of the approach. During the initial pilot test, in which 13 stories were aired, WLTX chief meteorologist Jim Gandy and news director Marybeth Jacoby were pleased by positive audience responses, especially in social media (J. Gandy and M. Jacoby 2019, personal communications). A quasi-experimental impact evaluation of the pilot test, reported below, found that WLTX viewers became more climate literate than viewers of competing stations (Zhao et al. 2014).

In an expanded pilot test beginning in 2012, Climate Matters materials were offered to TV weathercasters in 10 additional media markets. Audience feedback to these weathercasters was largely positive, although the expanded pilot test was not formally evaluated.

In 2013, Climate Matters materials were offered to any weathercaster in the United States who wanted them. By the fall of 2019-when the final data were collected for the impact evaluation analysis reported herein-the program had grown to support $797 \mathrm{TV}$ weathercasters at 433 local TV stations $(88 \%$ market penetration)-with 758 reporting in English and 39 reporting in Spanish language reporting materials. Between 2014 and 2019 on-air reporting about climate change by TV weathercasters had increased $5023 \%$-from 69 stories aired in 2014 to 3535 stories aired in 2019. Moreover, research by Perkins et al. (2018) found that the strongest predictor of a TV weathercaster reporting at least one climate story on air in the prior 12 months was participation in the Climate Matters program.

Concurrent with this rise in climate reporting by weathercasters, there has been a well-documented shift in weathercasters' views of climate change. One early study of the weathercaster community found that slightly less than one-quarter of TV weathercasters $(22 \%)$ agreed that "the theory of global warming is accepted by most atmospheric scientists" (Wilson 2002), while another showed that only $31 \%$ were convinced that global warming is caused primarily by human activities (Maibach et al. 2010). However, more recent studies have shown a substantial shift in weathercasters' views: in 2016 and 2017, attempted censuses of the TV weathercaster community showed that more than $90 \%$ of weathercasters agreed climate change is happening, and $80 \%$ attributed the cause of climate change to humans (Maibach et al. 2016, 2017). Indeed, a 2017 essay by Maibach and colleagues was titled "American TV weathercasters' views of climate change appear to be rapidly evolving" (Maibach et al. 2017). While no inferences can be made about the influence of the Climate Matters program on weathercasters views of climate change, the rapid evolution of weathercasters' views did occur concurrently with sustained efforts by the program staff to educate weathercasters about climate science and its local relevance (through workshops and webinars-see above), and with related efforts to identify and resolve long-standing conflicts within weathercaster community about human-caused climate change (Schweizer et al. 2014).

\section{Effectiveness and impact of Climate Matters}

Beyond the rapid growth in on-air climate change reporting by TV weathercasters, several studies have shown that such Climate Matters reporting influences viewers' understanding of climate change in ways consistent with climate literacy.

As mentioned above, an initial study assessed the impact of the Climate Maters pilot program in Columbia. In 2010 and 2011, then WLTX Chief Meteorologist J. Gandy produced and aired a series of 13 short, locally relevant 


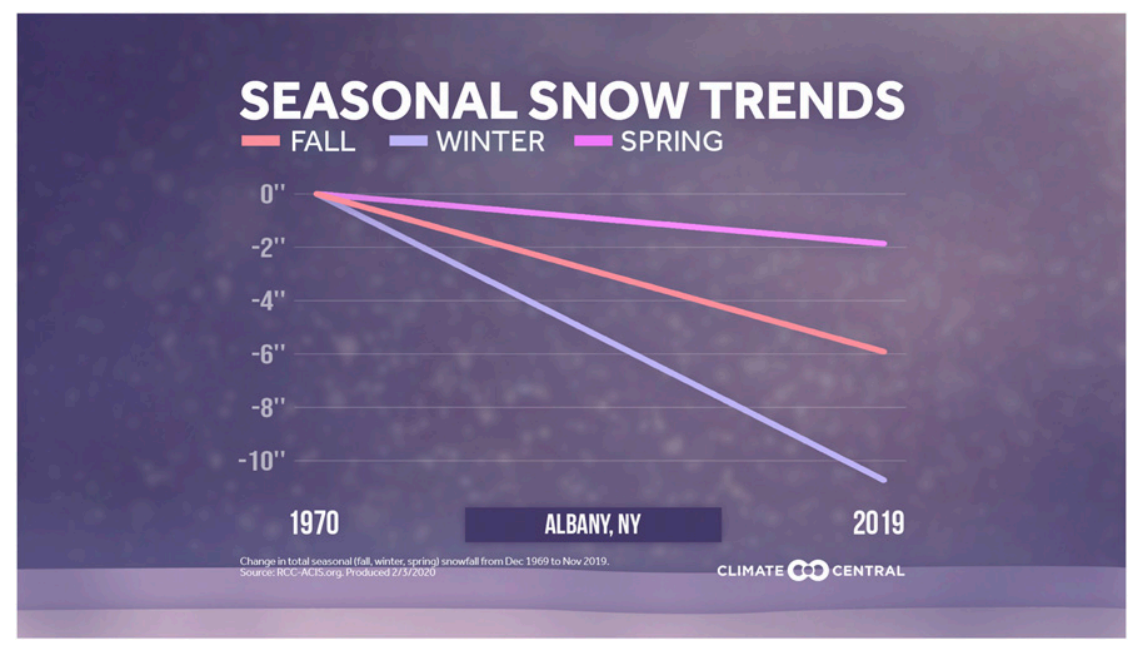

FIG. 2. Example of a cold-weather Climate Matters graphic.

climate change news segments; these videos were also hosted on the WLTX website, and Gandy included them in his blog and posted links to them on the Facebook and Twitter social media platforms. To assess the cumulative impact of these presentations, three surveys were conducted-the first collecting baseline climate knowledge and attitude data among Columbia local news viewers prior to the launch of the program, the second recontacting these same viewers after the year had passed to assess whether (and in what ways) their climate knowledge and attitudes had changed, and a third contacting a fresh cross-sectional new wave of Columbia local news viewers. This quasi-experimental evaluation found that, during the pilot-test year, WLTX viewers developed a more science-based understanding of climate change as relative to viewers of the competing local TV news stations (Zhao et al. 2014).

Anderson et al. (2013) conducted an experiment online with local news viewers in Columbia and Greenville, South Carolina, during and immediately after a summer heatwave in 2012. Participants were randomly assigned to watch one of two videos: a brief Climate Matters video in which Gandy explained the heat wave as a local manifestation of global warming or an equivalent-length video of Gandy giving a 72-h weather forecast predicting extreme heat. Although there was no main effect of watching the Climate Matters video versus the weather video on participants' global warming risk perception, there was a significant interaction such that viewers who watched the Climate Matters video and evaluated the weathercaster positively experienced increased risk perception. This effect was strongest among politically conservative viewers.

Using data from a random-digit dial survey of 2000 adult local TV news viewers in Virginia, Bloodhart et al.
(2015) assessed whether greater exposure to local TV weather forecasts influences people's perceptions of extreme weather in Virginia, and their perceptions about climate change more generally. They found that greater exposure to TV weather forecasts is associated with beliefs that extreme weather is becoming more frequent in Virginia, which in turn are associated with stronger beliefs and concerns about climate change. These associations were strongest for individuals who trust their local TV weathercaster as a source of information about climate change and for those who identify as politically conservative or moderate.

Feygina et al. (2020) conducted an online randomized controlled experiment in which local TV news viewers in Chicago, Illinois, and Miami, Florida, were randomly assigned to watch three short $(\sim 1-2 \mathrm{~min})$ videos featuring a prominent weathercaster from their media market. The treatment videos featured the weathercaster using Climate Matters materials to educate viewers about the impacts of climate change in their area, while the control videos featured weather forecasts by the same weathercaster. Relative to participants who watched weather forecasts, participants who watched climate reports became significantly more likely to understand that climate change is happening, is human caused, and is causing harm in their community; feel that climate change is personally relevant and express greater concern about it; and feel that they understand how climate change works and express greater interest in learning more about it. In short, these findings demonstrated that watching even a brief amount of localized climate reporting (less than $6 \mathrm{~min}$ ) delivered by local TV weathercasters helped viewers develop a more accurate understanding of global climate change as a locally and personally relevant problem. 


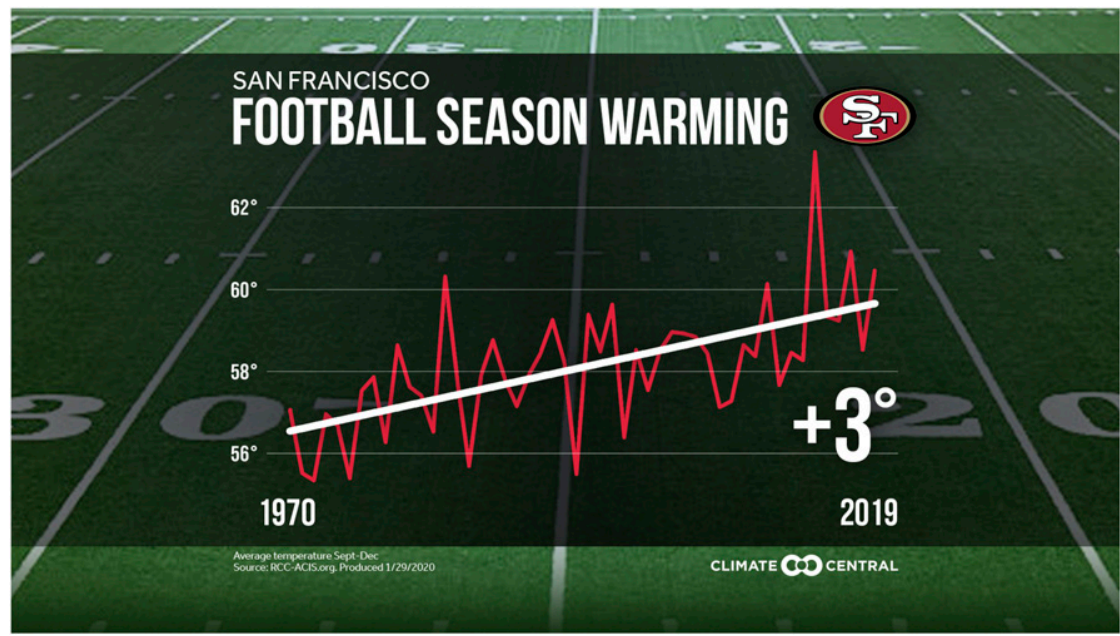

FIG. 3. Example of a current-event-themed Climate Matters graphic.

Taken together these studies show the potential of the Climate Matters program to educate the American public about climate change. The nationwide impact of climate reporting by weathercasters on public understanding of climate change, however, has yet to be demonstrated.

\section{Hypotheses and focus of the paper}

In this paper we present results from a study that assesses the impact of Climate Matters reporting by TV weathercasters on Americans' perceptions of climate change. We hypothesized 1) that reporting about climate change by TV weathercasters will influence the public's view of climate change, increasing (i) sciencebased understanding of and (ii) personal engagement with climate change and 2) that this effect will be stronger for people who pay more attention to local weather forecasts.

We examined several facets of the public's views of climate change-both understanding of the issue and personal engagement with the issue. Science-based understanding was conceptualized as agreement with three core components of scientific knowledge about climate change: that it is happening, that it is caused by humans, and that it is harmful-to people and to the natural environment. The aim of Climate Matters materials is to help Americans understand important scientific realities about climate change, and to do so in a personally relevant manner by showing local examples. Most Climate Matters story packages are designed to convey one or more of these core scientific facts-that climate change is happening (e.g., by showing warming trends over time), that it is caused by humans (e.g., by showing travel emissions at Thanksgiving), and that it is harmful, including in the viewers' community (e.g., by showing local impacts of coastal flooding) - especially the first and third of these facts. Past research examining the effectiveness of visual depictions of the effect of climate change on coastal flooding has shown that exposure to such messages influences these types of scientific beliefs, even overcoming political polarization around the issue of climate change (Bolsen et al. 2018, 2019). Therefore, it is important to assess the extent to which usage of Climate Matters materials is associated with public understanding of the science in these three ways.

In addition to science-based understanding of climate change, we assess personal engagement with the issue. We conceptualize personal engagement as both realization of the ways that climate change personally impacts an individual (personal experience with climate change) and the extent to which the individual engages others in discussion of climate change. Maio and Haddock (2007) argue that in general the more relevant the issue is to the individual, the more motivation the individual has to process the message; a process that has also been discussed in the context of climate change (Ereaut and Segnit 2007; Marin and Berkes 2013; Pearce et al. 2015). To the extent that the Climate Matters program is effective, individuals exposed to information about the local consequences of climate change through Climate Matters reporting should become more likely to process the ways that climate change is affecting them personally.

Climate Matters reporting also has the potential to encourage discussion among the public through several mechanisms: by increasing the amount of thinking an individual does about the topic; by decreasing the stigma associated with the topic; and by reducing 


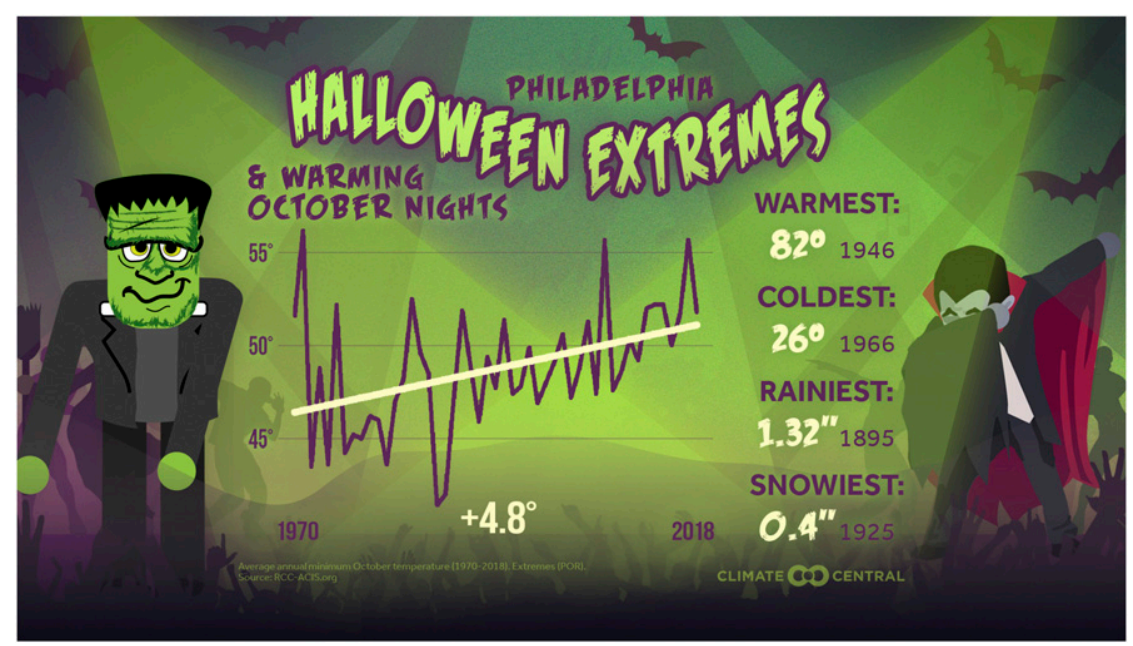

FIG. 4. Example of a holiday-themed Climate Matters graphic.

attitudinal ambivalence. De Boer and Velthuijsen (2001) find that "news exposure and conversations about the news are related experiences" (p. 154) and argue that increased cognitions about a topic that result from media exposure influence individuals to discuss that topic more-that is, thinking leads to discussion. Spiral of silence theory states that when an opinion is considered to be unpopular or in the minority (i.e., stigmatized), people are less likely to voice their opinions about it (Glynn and McLeod 1984). Reporting on climate change as a locally relevant issue by weathercasters has the potential to enhance the visibility of the issue and demonstrate that acceptance of the issue is normative, both of which can decrease stigma and enhance the probability that people exposed to such reporting will discuss the information with others. Ambivalence-holding both positive and negative attitudes about a topic—is also associated with lower probability of discussion (Armitage and Conner 2000). If exposure to Climate Matters reporting increases people's scientific understanding of climate change, their attitudinal ambivalence is likely to decrease. Indeed, research shows that increased attitudinal strength is associated with increased probability of discussion, as those with strong attitudes are more likely to share their perspective in interpersonal discussion-even about difficult topics (Matthes et al. 2010). Discussion of climate change is a helpful process in that discussions with trusted others lead people to learn important facts about the issue, which in turn encourages more discussion and strengthens a scientific understanding of the problem (Goldberg et al. 2019). Therefore, we assess whether exposure to Climate Matters is associated with higher rates of interpersonal discussion about climate change.

\section{Methods}

\section{a. Analytic overview}

To test the question of whether uptake of Climate Matters is associated with a more science-based understanding of climate change, we utilized a three-level multilevel model. Specifically, we modeled public understanding of climate change as a function of media market-level factors (level 3), time-varying factors (level 2), and individual-level (i.e., survey participant-level) factors (level 1). ${ }^{1}$

To measure public understanding of climate change and other individual-level factors, we used data from the Climate Change in the American Mind (CCAM) polling project, a long-term, nationally representative survey of Americans that has assessed public opinion about climate change biannually since $2010 .^{2}$ A total of 23635 participants, surveyed in 20 waves of the survey, were included in this analysis (see below for demographic details about the participants).

\footnotetext{
${ }^{1}$ Models were fit in Mplus. For the majority of models, we used maximum likelihood estimation with robust standard errors (MLR) (see the "All Coefficients" Microsoft Excel file in the online supplemental material for complete model results); because perception of human causation was measured dichotomously, we utilized Bayes estimation.

${ }^{2}$ An initial survey was conducted in 2008, but it is not included in this analysis because of shift-in-opinion trends from 2008 to 2010 and because of the change in frequency to biannual from 2010 onward. Furthermore, as is typical in long-term polling projects, not every question is asked in every wave. See the online supplemental material for a detailed description of which survey items were asked in each wave. A more complete description of the methodology of the CCAM project can be found online (https:// osf.io/w36gn/).
} 
The prevalence of Climate Matters reporting in the media market was tracked across time and utilized as our main independent variable (see description below for more details about how the tracking was conducted).

We test our research question via a dose-response model, that is, we test whether people within media markets with higher Climate Matters prevalence have increased scientific understanding about and higher perceptions of harm from climate change than those in markets with less Climate Matters prevalence. Furthermore, to strengthen our test, we assess whether this association between prevalence and public belief differs by the level of attention that an individual pays to the local weather forecast, testing whether the association between Climate Matters prevalence and scientific beliefs is stronger among those who pay more attention to local weather in comparison to those who pay less attention.

\section{b. Measurement}

We chose as the independent variable Climate Matters' prevalence in the media market and include two measures in its calculation within a media market: usage of the material and number of stations that utilized the material. The first is Climate Matters use. Use of Climate Matters material was tracked across multiple media types-television, Facebook, Twitter (both original posts and retweets), and on weathercaster blogs utilizing an extensive tracking process (see the Microsoft Word file in the online supplemental material for a detailed description of the tracking methodology). Use was aggregated within media market to create a measure of the number of stories in a market in a given time period. Based on previous work, which has shown that the effect of news about the environment on public opinion fades (or decays) exponentially with time windows between one and two months (MacKuen 1981; McCombs 2004), we calculated three measures of use, with time windows of decay to $5 \%$ at 24,30 , and 60 days [these are the three time windows that were tested and found to be the most powerful with similar issues in Watt et al. (1993); additionally, we utilize their decay functions to compute our decayed effects]. Thus, CM material that was utilized closer to the date of the survey was weighted more heavily than that which had been used previously (Fig. S1 in the online supplemental material gives the decay curves). At 24 days, the $\mathrm{CM}$ use score ranged from 0 to 16.63 , with an average of 0.25 stories ( $\operatorname{std} \mathrm{dev}=0.81)$, at 30 days use scores ranged from 0 to 17.85 , with an average of $0.32(\operatorname{std~dev}=0.96)$, and at 60 days use ranged from 0 to 22.94, with an average of $0.59(\operatorname{std} d e v=1.63)$. Therefore, for each media market, for each date of the survey, three measures of use were calculated, decayed in the manner described above.
The second measure of use is number of TV stations that utilized Climate Matters material. To capture how widespread the use of Climate Matters material was across stations (i.e., many stations using the material vs one station using the material), we calculated the number of TV stations within a media market that had used the material in the past 24, 30, and 60 days. At the 24- and 30-day time specifications the number of stations ranged from 0 to 7 , and at the 60-day time specification the number of stations ranged from 0 to 9 ; the average at 24 days was 0.30 stations ( $\operatorname{std} \mathrm{dev}=0.62$ ), the average at 30 days was 0.33 stations ( $\operatorname{std} \mathrm{dev}=0.66$ ), and the average at 60 days was 0.48 stations ( $\operatorname{std}$ dev $=0.82$ ).

To compute the final measures of Climate Matters prevalence that were utilized in the models, we standardized the two components (use and number of stations) and averaged them, creating prevalence measures within 24-, 30-, and 60-day time windows (correlation coefficients between use and number of stations were $r_{24 \mathrm{Days}}=0.706, r_{30 \mathrm{Days}}=0.702$, and $r_{60 \mathrm{Days}}=0.684$; all significance levels $p$ were less than 0.001). This final measure was then modeled as a level-2 (time varying) independent variable.

\section{c. Moderator: Attention to local weather forecasts}

As described in the analysis overview, we tested whether the effect of Climate Matters prevalence was stronger for people who routinely pay more attention to the local weather forecast. This was measured with the following question: "How closely do you follow news about each of the following?" Attention to several types of news was included, but for the purposes of this study we focus only on responses to the prompt "the local weather forecast." Responses ranged from "not at all" (coded as 1) to "very closely" (coded as 4), with an average of 3.03 (closest to "somewhat closely"; std dev $=0.864$ ).

\section{d. Dependent variables}

We included multiple measures of people's views of climate change belief to assess the types of outcomes that Climate Matters might impact.

First, we assessed two core indicators of perception of climate change: 1) certainty in the reality and 2) human causation of climate change. Certainty in the reality of climate change was assessed with two items: (i) "Recently, you may have noticed that global warming [climate change] [note: participants saw only one label—global warming or climate change] has been getting some attention in the news. Global warming [Climate change] refers to the idea that the world's average temperature has been increasing over the past 150 years, may be increasing more in the future, and that the world's climate may change as a result. What do you think: Do 
you think that global warming is happening?"- -response options were "yes," "no," and "don't know"; (ii) "How sure are you that global warming is [not] happening?" with response options of "extremely sure global warming is [not] happening," "very sure global warming is [not] happening," "somewhat sure global warming is [not] happening," and "not at all sure global warming is [not] happening." Responses are coded such that 1 was "extremely sure global warming is not happening" and 9 was "extremely sure global warming is happening" with "don't know" coded as the midpoint of 5. The average response was 6.42 (closest to "not at all sure global warming [climate change] is happening"; std $\operatorname{dev}=2.26)$. Perceived human causation of climate change was assessed with an item that reads: "Assuming global warming is happening, do you think it is:" and coded such that "mostly human caused" received a value of 1 (51.9\% of respondents) and all other answers (except missing; $0.4 \%$ of respondents) were coded as $0(48.1 \%$ of respondents).

Next, we assessed six harm perceptions, ranging from proximal to distant harms. Participants were asked: "How much do you think global warming will harm: 1) you personally [personal harm; mean $=2.27$; S.D. $=$ 1.01], 2) your family [family harm; mean $=2.39$; std $\operatorname{dev}=1.03$ ], 3) your community [community harm; mean $=2.43$; std dev $=1.03], 4)$ people in the United States [U.S. harm; mean $=2.69 ;$ std dev $=1.06], 5$ ) future generations of people [future generations harm; mean $=$ 3.15; std dev $=1.08]$, and 6) plant and animal species [plant and animals harm; mean $=3.12 ;$ std dev $=1.08]$ ?" Response options range from "not at all" (coded as 1) to "a great deal" (coded as 4).

Last, we assess two personal indicators: 1) personal experience and 2) discussion of climate change. Personal experience was measured with an item that reads: "How much do you agree or disagree with the following statements? I have personally experienced the effects of global warming [climate change]." with responses that range from "strongly disagree" (coded as 1) to "strongly agree" (coded as 4), with an average response of 2.08 (closest to "somewhat disagree"; std $\operatorname{dev}=0.94)$. Discussion of climate change was assessed with an item that reads: "How often do you discuss global warming with your family and friends?", and responses range from "never" (coded as 1) to "often" (coded as 4), with an average response of 2.11 (closest to "rarely"; std dev $=0.88$ ).

\section{e. Mechanism: Recall of weathercaster presenting information about climate change}

To test whether any impact of Climate Matters on public opinion is due to recall of the information presented, we assessed recollection of seeing a story about global warming with an item that read, "In the past 12 months, about how often, if ever, have you seen a special news story about global warming by a local TV weathercaster?"; in some waves the question was, "During the past 12 months, about how many times, if ever, have you seen or heard a local TV weathercaster talking about how global warming is influencing your local weather?" Responses ranged from "never" (coded as 1; also coded as 1 were "not sure" or "not applicable-I don't watch the local weather forecast") to "more than five times" (coded as 4), with an average response of 1.95 (closest to "once or twice"; std dev = 1.14).

\section{f. Individual-level (level 1) controls}

At the individual level, we included several controls: age, education, gender, political ideology, and whether the participant received questions with the wording global warming or climate change. Age, education, income, and gender were provided to us by the survey panel provider. Average age was 50.59 ( std dev $=16.88)$. Education response options ranged from "no formal education" (coded as 1) to "professional or doctorate degree" (coded as 14); the average was 10.41 (closest to "some college, no degree"; std dev = 1.97). Income response options ranged from "less than $\$ 5,000 "$ (coded as 1 ) to " $\$ 250,000$ or more" (coded as 21$)$; the average was 12.33 (closest to " $\$ 50,000$ to $\$ 59,999 "$ "; std $\mathrm{dev}=$ 4.51). Gender had response options of male (coded as $1 ; 49.4 \%$ ) and female (coded as 2; 50.6\%). Political ideology was measured with an item that read, "In general, do you think of yourself as...," with response options that ranged from "very liberal" (coded as 1) to "very conservative" (coded as 5), with an average of 3.12 (closest to "moderate, middle of the road"; std $\operatorname{dev}=1.07)$. In one wave of the survey a split half experiment was run, with half of respondents receiving questions that included the terminology "global warming" (coded as 1) and the other half receiving the terminology of "climate change" (coded as 2); this resulted in 827 participants $(3.5 \%)$ included in this analysis having received the terminology "climate change" and the remaining 22808 participants $(96.5 \%)$ having received the terminology "global warming."

\section{g. Time-level (level 2) controls}

At the time level, we nested by the date that the participant finished the survey (that date was then used to calculate $\mathrm{CM}$ usage in the previous 24,30 , and 60 days, as described above). We also included the 
number of months from the first survey date as a control for the passage of time.

\section{h. Media market-level (level 3) controls}

At the media market level, we included the controls of population size, temperature, market-level political ideology, economic situation, and number of cases from the market included in the model. Population size was garnered from the database SimplyMap, which utilized data from the Bureau of the Census, and was an aggregate sum of all counties included in a media market (mean $=142577$; std dev $=306982$; we logged the population for the final models to minimize the impact of outliers). Temperature was the annual average temperature of the market and was again garnered from the SimplyMap database, which utilized data from the National Climatic Data Center. We averaged the average temperature of all of the counties in a market (mean $=55.33$; std dev $=9.04)$. Political ideology of the market was measured as the percent of a market that identifies as liberal and was also garnered from the SimplyMap database, which utilized data from the SimmonsLOCAL consumer survey (mean $=14.3 ;$ std dev $=2.91)$. To measure economic hardship, we utilized the area deprivation index (ADI) developed by Singh (2003) that utilizes 17 markers of socioeconomic status from the census, including such things as white-collar job percentage, income level, and median home value. Higher values indicate greater economic deprivation (range [66.13, 116.95], mean $=107.46$, and std dev $=7.35)$. Last, we include the number $N$ of participants in the model from each market and for each outcome as a control to assess representation in the model (range $=[0,1185]$, and means varied by outcome; see Table S1 of the online supplemental material for more detail).

\section{Results}

\section{a. Is Climate Matters prevalence associated with more scientific beliefs about climate change, perception of harm from climate change, and personal reaction to climate change?}

As outlined in the analytical overview, to assess this question, we fit multilevel models (one for each outcome), with individual data (including the outcome and individual controls like age, education, gender, income, political ideology, and whether the participant saw questions with global warming or climate change wording) at level 1, Climate Matters prevalence at the date of the survey at level 2, and market-level data (including ADI, political ideology of the market, population size, average temperature and number of cases from the market in the model) at level 3.

We were faced with a modeling choice: because we had data prior to when Climate Matters was launched, a "zero" on Climate Matters prevalence indicated something different before and after the launch of Climate Matters (at dates before the launch, zero indicates CM had not yet begun; at dates after the launch, zero indicates CM had not been used) - therefore, we had to choose whether to model only data from after the Climate Matters program was launched or to also include prior waves of data. On the one hand, excluding prior waves allows for clarity on the effect of "zero"-whether it was not yet launched or whether no Climate Matters material had been used; on the other, it is useful to include all time periods in the model. To maintain transparency about analytic choices, we report both analysis types here. In the models which retain waves prior to the launch of Climate Matters, we include a binary indicator that is set to 0 for survey dates that were before the launch of Climate Matters and 1 for survey dates that were postlaunch. In the models that include waves only post-Climate Matters launch we include an aggregated mean score of the outcome from all waves prior as a control. See Table 1 for all prevalence coefficients and the online supplemental material for coefficients of all predictors in the models.

Results show that people from media markets that had higher Climate Matters prevalence had more scientific beliefs (stronger certainty in the reality of climate change and perception of human causation) than people from media markets with less Climate Matters prevalence. This finding held across all model specifications (with each time window: 24, 30, and 60 days, and both when modeling only after CM was introduced and when including waves from both before and after CM launch) when predicting certainty in the reality of climate change but was not as strong when predicting perception of human causation (significant only in the 24and 60-day all-time-periods models).

Additionally, people from media markets that had higher Climate Matters prevalence had higher perceptions of harm for the more proximate measures (personal, family, and community harm) in comparison with people from media markets with less Climate Matters prevalence. There were some slight differences between time windows (effects were strongest in the 24-day window) and modeling approaches (effects were weaker or nonsignificant in the after-CM-launch models).

However, there was no evidence of differences in perceptions of personal experience between markets of differing Climate Matters prevalence. There was some evidence of differences in rates of discussion about 
TABLE 1. Relationship between Climate Matters prevalence and outcomes, across three time windows and with two model specifications. All entries are unstandardized regression coefficients for Climate Matters prevalence on each outcome (run as separate models). A plus sign indicates $p<0.10$, one asterisk is $p<0.05$, two asterisks is $p<0.01$, and three asterisks is $p<0.001$ (all $p$ values are two tailed).

\begin{tabular}{|c|c|c|c|c|c|c|}
\hline & \multicolumn{2}{|c|}{ 24-day window } & \multicolumn{2}{|c|}{ 30-day window } & \multicolumn{2}{|c|}{ 60-day window } \\
\hline & $\begin{array}{l}\text { All time } \\
\text { periods }\end{array}$ & $\begin{array}{c}\text { After CM } \\
\text { launch }\end{array}$ & $\begin{array}{l}\text { All time } \\
\text { periods }\end{array}$ & $\begin{array}{c}\text { After CM } \\
\text { launch }\end{array}$ & $\begin{array}{l}\text { All time } \\
\text { periods }\end{array}$ & $\begin{array}{c}\text { After CM } \\
\text { launch }\end{array}$ \\
\hline $\begin{array}{l}\text { Certainty in the reality of climate } \\
\text { change }\end{array}$ & $0.052 * *$ & $0.055^{*}$ & $0.050 * *$ & $0.051 *$ & $0.048 * *$ & $0.049^{*}$ \\
\hline Human causation & $0.019 *$ & 0.009 & 0.020 & 0.009 & $0.020 *$ & 0.007 \\
\hline Personal harm & $0.015^{*}$ & 0.011 & $0.015^{*}$ & 0.012 & $0.018 * *$ & $0.014^{+}$ \\
\hline Family harm & $0.016^{*}$ & 0.011 & $0.017 * *$ & 0.012 & $0.019 * *$ & $0.014 *$ \\
\hline Community harm & $0.015^{*}$ & 0.010 & $0.015^{*}$ & 0.010 & $0.017 * *$ & 0.012 \\
\hline U.S. harm & 0.008 & 0.002 & 0.010 & 0.003 & 0.013 & 0.005 \\
\hline Future generations harm & 0.001 & -0.002 & 0.003 & 0.000 & 0.006 & 0.002 \\
\hline Plants and animals harm & 0.010 & 0.006 & 0.011 & 0.007 & 0.013 & 0.007 \\
\hline Personal experience & 0.009 & -0.001 & 0.007 & -0.003 & 0.007 & -0.005 \\
\hline Discussion & $0.012^{+}$ & -0.006 & $0.013^{+}$ & -0.005 & $0.015^{*}$ & -0.007 \\
\hline
\end{tabular}

global warming between markets with different levels of Climate Matters prevalence (significant in the 60-day all-time-periods model specification and marginally significant in the 24- and 30-day all-time-periods model specifications).

b. Does the association between Climate Matters and scientific beliefs about climate change, perception of harm from climate change, and personal reaction to climate change, differ by attention to the local weather forecast?

We follow the same general modeling approach as described above, with the addition of a cross-level interaction between Climate Matters prevalence and attention to the local weather forecast (see Table 2 for all interaction coefficients and the online supplemental material for all coefficients in the models). There was very little evidence of any interaction between prevalence and attention when predicting the outcomes. The sole exception is when predicting personal experience in the 60 day window (marginally significant in the all time periods specification). All other interactions were not significant.

c. Did people from markets with higher CM prevalence recall seeing information about $G W$ from weathercasters? Were those who attended more to the local weather more likely to recall seeing information in markets with high prevalence than those who indicated less attention?

We tested whether people from markets with greater $\mathrm{CM}$ prevalence recalled seeing more information about GW from weathercasters, utilizing the same modeling approaches as above. As this outcome was only measured

TABLE 2. Relationship between the interaction of Climate Matters prevalence and attention to local weather forecast and outcomes, across three time windows and with two model specifications. All entries are unstandardized regression coefficients for the interaction of Climate Matters prevalence and attention to the local weather on each outcome (run as separate models). A plus sign indicates $p<0.10$, one asterisk is $p<0.05$, two asterisks is $p<0.01$, and three asterisks is $p<0.001$ (all $p$ values are two tailed).

\begin{tabular}{|c|c|c|c|c|c|c|}
\hline & \multicolumn{2}{|c|}{ 24-day window } & \multicolumn{2}{|c|}{ 30-day window } & \multicolumn{2}{|c|}{ 60-day window } \\
\hline & $\begin{array}{l}\text { All time } \\
\text { periods }\end{array}$ & $\begin{array}{l}\text { After CM } \\
\text { launch }\end{array}$ & $\begin{array}{l}\text { All time } \\
\text { periods }\end{array}$ & $\begin{array}{l}\text { After CM } \\
\text { launch }\end{array}$ & $\begin{array}{l}\text { All time } \\
\text { periods }\end{array}$ & $\begin{array}{l}\text { After CM } \\
\text { launch }\end{array}$ \\
\hline $\begin{array}{l}\text { Certainty in the reality of climate } \\
\text { change }\end{array}$ & 0.015 & 0.016 & 0.022 & 0.022 & 0.027 & 0.029 \\
\hline Human causation & 0.008 & -0.001 & 0.013 & 0.005 & 0.008 & -0.003 \\
\hline Personal harm & -0.003 & -0.003 & -0.001 & -0.002 & 0.002 & 0.001 \\
\hline Family harm & 0.004 & 0.003 & 0.005 & 0.004 & 0.009 & 0.009 \\
\hline Community harm & -0.001 & -0.002 & 0.000 & -0.001 & 0.004 & 0.003 \\
\hline U.S. harm & 0.000 & 0.000 & 0.001 & 0.001 & 0.006 & 0.006 \\
\hline Future generations harm & -0.002 & -0.001 & 0.000 & 0.001 & 0.001 & 0.002 \\
\hline Plants and animals harm & 0.000 & 0.001 & 0.002 & 0.003 & 0.002 & 0.003 \\
\hline Personal experience & 0.007 & 0.004 & 0.010 & 0.007 & $0.016^{+}$ & 0.013 \\
\hline Discussion & 0.001 & 0.006 & 0.003 & 0.008 & 0.004 & 0.009 \\
\hline
\end{tabular}


after the launch of Climate Matters, we use only the after $\mathrm{CM}$ launch model specification (with no control for prior levels). Results show no association between prevalence of $\mathrm{CM}$ in a market and recall of having seen global warming information, regardless of the time window (at 24 days $=0.007, p=$ not significant; at 30 days $=0.006$, $p=$ not significant; at 60 days $=0.003, p=$ not significant).

In addition, we tested whether those who attended more to local weather forecast had more recall. Results show no association between prevalence of $\mathrm{CM}$ in a market and recall of having seen global warming information, regardless of the amount of attention paid, or of the time window (interaction at 24 days $=0.004, p=$ not significant; at 30 days $=0.004, p=$ not significant; at 60 days $=0.006, p=$ not significant $)$.

\section{Discussion}

Results from this analysis demonstrate a positive association between the frequency of use of Climate Matters materials by TV weathercasters and the public's understanding of key scientific facts about climate change. Specifically, across all time windows and model specifications there was an association between the prevalence of weathercasters' use of Climate Matters materials and public certainty in the reality of climate change. Additionally, there was evidence of association between use of Climate Matters materials and public perceptions of several types of locally relevant harm from climate change-including personal, family, and community harm. There was also some, albeit limited, evidence of an association between prevalence and public discussions about climate change. Conversely, there was no evidence of an association between use of Climate Matters materials and public perceptions of having personally experienced global warming, or of more distant types of harm (harm to the United States, to future generations, and to plants and animals). Taken together with other effectiveness evaluations of Climate Matters (including Anderson et al. 2013; Feygina et al. 2020; Zhao et al. 2014), this study provides further evidence of the impact of the Climate Matters program.

However, it is important to note that there are many limitations inherent in the approach of this analysis. First, there is a low signal-to-noise ratio. There has been relatively limited use of Climate Matters (although it has grown exponentially over time), meaning there is a small signal to detect. Additionally, there is a lot of other climate change information that has been disseminated over the last 9 years, meaning there is a lot of other material-along with personal experiences-that could affect our outcomes that are not captured in this model.
Furthermore, we have small, nonrandom, cross-sectional samples of individuals within each media market, resulting in low reliability of measurement at the market level (i.e., low intraclass correlation). This means that market-level differences are hampered by problematic measurement due to low sample sizes and that across time change is difficult to assess due to the cross-sectional nature of the data. Likely as a result of these two limitations, we were unable to estimate what would have been the best test of our research question - a dual trajectory growth model-because it would not converge.

Additionally, we do not have information about the extent to which individuals were exposed to Climate Matters material, rather we have information about how frequently CM material was aired, on how many stations, and how much participants report attending to local news about the weather. Even those at the highest levels of attention, however, may not have seen the Climate Matters material. Compounding this limitation, we do not see evidence that the association between prevalence and outcomes is stronger for those who indicated high levels of attention to the local weather and we did not see any association between prevalence and recall of seeing weathercasters present about climate change. Prior research has shown that self-reported news exposure is "severely" overreported (Prior 2009), therefore it is difficult to know whether this lack of association is due to an actual lack of an effect or to problems inherent in our use of self-reported media use measures.

Furthermore, we cannot fully rule out the counterexplanation that media markets which already had high levels of acceptance of climate change and perceptions of harm had weathercasters that adopted Climate Matters usage at a higher rate than those media markets with lower levels (in other words, reverse causation of the effects observed). However, given that we control for political ideology of the media market in all models, and prior levels of the outcome in the post-CM launch models, we feel that we have reasonable safeguards against this alternate explanation of the results. That is, the effects we observe are above and beyond the market's political leanings (in all models) and prior levels of the outcomes (in the post CM models), both of which might influence weathercaster uptake of Climate Matters.

In terms of measurement, for many items we have only a single measure, which is less than ideal. Additionally, due to the exponential growth of usage of Climate Matters materials and resource constraints, tracking of Climate Matters usage changed over time (see the file on the tracking methodology in the online supplemental material 
for further details); while we attempted to adjust for this variation over time, it is still a notable limitation. Furthermore, given the nature of usage (i.e., that meteorologists had complete control over the time, method, and platform of how to use the material), tracking likely did not capture all usage. While this is a notable limitation, we have no reason to suspect that this undercapture of usage varies systematically across media markets, which would be the most damaging to the assumptions of our models.

We take these limitations seriously and note that they provide important boundaries for our confidence in these results. However, assessing the impact of a national media program-for which there are varying levels of implementation across time and media market-on public opinion is hugely difficult, and there is no ideal approach that is practicable (financially and/or with control). Therefore, we take an approach analogous to the "intent to treat" methodology utilized in epidemiology, by which we model the "treatment" as offered (i.e., typically as prescribed, or in this case, Climate Matters material that was utilized in the market), rather than implemented (i.e., the patient adhering to the treatment, in this case participant exposure to the message). This necessarily constrains our confidence in these results.

Given these limitations, there are important opportunities for future research. First, as many of the authors of this paper have been intimately involved in the development and production of the Climate Matters program, further evaluations of the impact of Climate Matters on public understanding of climate change by independent researchers would be helpful. Additionally, further research on how public consumers of local TV news interpret reporting that is based on Climate Matters material, and how they integrate it into their lived experience of weather and climate would also be useful. Ideally, looking beyond cognitive impacts, such research would examine whether increased scientific understanding results in individual and collective action to adapt to or limit climate change. Such research would also have broad value to the climate education community. Last, research examining the impacts of more nuanced facets of how weathercasters report on climate change would be helpful-including moderating influences (such as placement of the material within the weather versus news sections of the broadcast; demographics of the broadcast meteorologist such as age, race, and gender) — rather than just how much reporting was done.

\section{Conclusions}

The Climate Matters program has been enormously successful in engaging the weathercaster community with the subject of climate change. Discussion of climate change by the weathercaster community has increased exponentially, and prior survey research with weathercasters has shown that participation in the Climate Matters program is the factor most strongly associated with reporting about climate change on air (Perkins et al. 2018). The current study adds to the growing evidence that $\mathrm{CM}$ material has the potential to inform the public about the reality and risks of climate change.

Acknowledgments. We gratefully acknowledge the National Science Foundation for their funding of this work (DRL-1713450 and DRL-1422431). We also acknowledge Will Atkinson from Climate Central, Eryn Campbell from George Mason University, and Amanda Borth from George Mason University for their assistance in the preparation of this paper.

Data availability statement. The data for this project are available online on the Open Science Framework (https://doi.org/10.17605/OSF.IO/HXZMJ).

\section{REFERENCES}

Anderson, A. A., T. A. Myers, E. W. Maibach, H. Cullen, J. Gandy, J. Witte, N. Stenhouse, and A. Leiserowitz, 2013: If they like you, they learn from you: How a brief weathercaster-delivered climate education segment is moderated by viewer evaluation of the weathercaster. Wea. Climate Soc., 5, 367-377, https:// doi.org/10.1175/WCAS-D-12-00051.1.

Armitage, C. J., and M. Conner, 2000: Attitudinal ambivalence: A test of three key hypotheses. Pers. Soc. Psychol. Bull., 26, 1421-1432, https://doi.org/10.1177/0146167200263009.

Ballew, M. T., and Coauthors, 2019: Climate change in the American mind: Data, tools, and trends. Environ. Sci. Policy Sustainable Dev., 61, 4-18, https://doi.org/10.1080/ 00139157.2019.1589300.

Bloodhart, B., E. Maibach, T. Myers, and X. Zhao, 2015: Local climate experts: The influence of local TV weathercaster information on climate change perceptions. PLOS ONE, 10, e0141526, https://doi.org/10.1371/journal.pone.0141526.

Bolsen, T., J. Kingsland, and R. Palm, 2018: The impact of frames highlighting coastal flooding in the USA on climate change beliefs. Climatic Change, 147, 359-368, https://doi.org/10.1007/ s10584-018-2143-0.

,-- , and -2019 : Counteracting climate science politicization with effective frames and imagery. Sci. Commun., 41, 147-171, https://doi.org/10.1177/1075547019834565.

de Boer, C., and A. S. Velthuijsen, 2001: Participation in conservations about the news. Int. J. Public Opin. Res., 13, 140-158, https://doi.org/10.1093/ijpor/13.2.140.

DeMuth, J., J. Lazo, and R. Morss, 2011: Exploring variations in people's sources, uses and perceptions of weather forecasts. Wea. Climate Soc., 3, 177-192, https://doi.org/10.1175/ 2011WCAS1061.1.

Ereaut, G., and N. Segnit, 2007: Warm words II: How the climate story is evolving and the lessons we can learn for 
encouraging public action. Energy Saving Trust Doc., 52 pp., https:/www.ippr.org/files/images/media/files/publication/ 2011/05/warmwordsfull_1596.pdf.

Feygina, I., T. Myers, B. Placky, S. Sublette, T. Souza, J. TooheyMorales, and E. Maibach, 2020: Localized climate reporting by TV weathercasters enhances public understanding of climate change as a local problem: Evidence from a randomized controlled experiment. Bull. Amer. Meteor. Soc., 101, E1092-E1100, https://doi.org/10.1175/BAMS-D19-0079.1.

Glynn, C. J., and J. M. McLeod, 1984: Public opinion du jour: An examination of the spiral of silence. Public Opin. Quart., $\mathbf{4 8}$, 731-740, https://doi.org/10.1086/268879.

Goldberg, M., S. van der Linden, E. Maibach, and A. Leiserowitz, 2019: Discussing global warming leads to greater acceptance of climate science. Proc. Natl. Acad. Sci. USA, 116, 14804 14 805, https://doi.org/10.1073/pnas.1906589116.

Henson, R., 2010: Weather on the Air: A History of Broadcast Meteorology. Amer. Meteor. Soc., 241 pp.

Jay, A., and Coauthors, 2018: Overview. Impacts, Risks, and Adaptation in the United States: Fourth National Climate Assessment, Vol. II, D. R. Reidmiller et al., Eds., U.S. Global Change Research Program, 33-71, https://doi.org/10.7930/ NCA4.2018.CH1.

Leiserowitz, A., E. Maibach, C. Roser-Renouf, G. Feinberg, and S. Rosenthal, 2015: Climate change in the American mind: March 2015. Yale University Program on Climate Change Communication and George Mason University Center for Climate Change Communication Rep., 62 pp., https:// climatecommunication.yale.edu/wp-content/uploads/2015/ 04/Global-Warming-CCAM-March-2015.pdf.

,-- S. Rosenthal, J. Kotcher, P. Bergquist, M. Ballew, M. Goldgerg, and A. Gustafson, 2019: Climate change in the American mind: April 2019. Yale University Program on Climate Change Communication and George Mason Center for Climate Change Communication University Rep. 70 pp., https://doi.org/10.17605/OSF.IO/CJ2NS.

Lorenzoni, I., N. Pidgeon, and R. O'Connor, 2005: Dangerous climate change: The role for risk research. Risk Anal., 25, 1387-1398, https://doi.org/10.1111/j.1539-6924.2005.00686.x.

MacKuen, M., 1981: Social communication and the mass policy agenda. More than News; Media Power in Public Affairs, M. B. Mackuen and S. L. Coombs, Eds., Sage, 19-144.

Maibach, E., 2019: Increasing public awareness and facilitating behavior change: Two guiding heuristics. George Mason University Center for Climate Change Communication Rep., 17 pp., https://www.climatechangecommunication.org/ wp-content/uploads/2018/06/Maibach-Two-hueristics-September2015-revised.pdf.

- K. Wilson, and J. Witte, 2010: A national survey of television meteorologists about climate change: Preliminary findings. George Mason University Center for Climate Change Communication Rep., 24 pp., https://www.sealevel.info/ AMS/2010_Survey_Report.pdf.

_- R. Mazzone, R. Drost, T. Myers, and B. Woods Placky, 2015: A national survey of broadcast meteorologists about climate change: Initial findings. Center for Climate Change Communication, George Mason University, 70 pp., http:// climatechangecommunication.org/wp-content/uploads/2015/04/ 2015-Broadcast-Met-Final-Survey-Report-rev.compressed.pdf. , H. Cullen, B. Placky, J. Witte, K. Seitter, N. Gardiner, T. Myers, and S. Sublette, 2016: TV meteorologists as local climate educators. Oxford Research Encyclopedia of Climate
Science, Oxford University Press, https://doi.org/10.1093/ acrefore/9780190228620.013.505.

— , and Coauthors, 2017: TV weathercasters' views of climate change appear to be rapidly evolving. Bull. Amer. Meteor. Soc., 98, 2061-2064, https://doi.org/10.1175/BAMS-D-1500206.1.

Maio, G. R., and G. Haddock, 2007: Attitude change. Social Psychology: Handbook of Basic Principles, 2nd ed. A. W. Kruglanski and E. T. Higgins, Eds., Guilford, 565-586.

Marin, A., and F. Berkes, 2013: Local people's accounts of climate change: To what extent are they influenced by the media? Wiley Interdiscip. Rev.: Climate Change, 4, 1-8, https://doi.org/ 10.1002/wcc.199.

Matthes, J., K. R. Morrison, and C. Schemer, 2010: A spiral of silence for some: Attitude certainty and the expression of political minority opinions. Commun. Res., 37, 774-800, https:// doi.org/10.1177/0093650210362685.

McCombs, M., 2004: Setting the Agenda: The Mass Media and Public Opinion. Polity, 208 pp.

Meldrum, H. M., D. Szymanski, E. A. Oches, and P. T. Davis, 2017: Speaking out or staying quiet on climate change: Broadcast meteorologists influenced by the need to be pithy, popular and politically cautious. Climate Change Adaptation in North America, W. L. Filho and J. M. Keenan, Eds., Springer International Publishing, 261-277.

Pearce, W., B. Brown, B. Nerlich, and N. Koteyko, 2015: Communicating climate change: Conduits, content, and consensus. Wiley Interdiscip. Rev.: Climate Change, 6, 613626, https://doi.org/10.1002/wcc.366.

Perkins, D., E. Maibach, N. Gardiner, J. Witte, B. Ward, B. Placky, K. Seitter, and H. Cullen, 2017: Most Americans want to learn more about climate change. Bull. Amer. Meteor. Soc., 98, 1103-1107, https://doi.org/10.1175/BAMSD-16-0097.1.

, T. Myers, Z. Francis, R. Mazzone, and E. Maibach, 2018: Attributes of weathercasters who engage in climate change education outreach. Wea. Climate Soc., 10, 487-500, https:// doi.org/10.1175/WCAS-D-17-0025.1.

Pew Research Center, 2013: The state of the news media 2013: Annual report on American journalism. Pew Research Center Project for Excellence in Journalism Rep., 444 pp., https:// assets.pewresearch.org.s3.amazonaws.com/files/journalism/ State-of-the-News-Media-Report-2013-FINAL.pdf.

Pidgeon, N., 2012: Climate change risk perception and communication: Addressing a critical moment? Risk Anal., 32, 951-956, https://doi.org/10.1111/j.1539-6924.2012.01856.x.

Placky, B., and Coauthors, 2015: Climate Matters: A comprehensive educational resource for broadcast meteorologists. Bull. Amer. Meteor. Soc., 97, 709-712, https://doi.org/10.1175/ BAMS-D-14-00235.1.

Prior, M., 2009: The immensely inflated news audience: Assessing bias in self-reported news exposure. Public Opin. Quart., 73, 130-143, https://doi.org/10.1093/poq/nfp002.

Rowan, K., and Coauthors, 2018: Best practices of "innovator" TV meteorologists who act as climate change educators. Risk and Health Communication in an Evolving Media Environment, D. O'Hair, Ed., Routledge, 123-156.

Schweizer, V., S. Cobb, W. Schroeder, G. Chau, and E. Maibach, 2014: TV weathercasters and climate education in the shadow of climate change conflict. Culture, Politics and Climate Change: How Information Shapes Our Common Future, D. Crowm and M. Boykoff, Eds., Routledge, 83101. 
Singh, G. K., 2003: Area deprivation and widening inequalities in US mortality, 1969-1998. Amer. J. Public Health, 93, 11371143, https://doi.org/10.2105/ajph.93.7.1137.

Timm, K., D. Perkins, T. Myers, B. Placky, and E. Maibach, 2020: Reporting on climate change by broadcast meteorologists: A national assessment. Bull. Amer. Meteor. Soc., 101, E129E140, https://doi.org/10.1175/BAMS-D-18-0225.1.

Watt, J. H., M. Mazza, and L. Snyder, 1993: Agenda-setting effects of television news coverage and the effects decay curve. Commun. Res., 20, 408-435, https://doi.org/10.1177/ 009365093020003004.

Wilson, K., 2002: Forecasting the future: How television weathercasters' attitudes and beliefs about climate change affect their cognitive knowledge on the science. Sci. Commun., 24, 246268, https://doi.org/10.1177/107554702237849.

Zhao, X., and Coauthors, 2014: Climate change education through TV weathercasters: Results of a field experiment. Bull. Amer. Meteor. Soc., 95, 117-130, https://doi.org/10.1175/BAMS-D-12-00144.1. 